\title{
Eighteen-year follow-up demonstrates prolonged survival and enhanced quality of life for octogenarians after coronary artery bypass grafting
}

Paul A. Kurlansky, MD, Donald B. Williams, MD, Ernest A. Traad, MD, Melinda Zucker, BSN, and

George Ebra, EdD

Objective: Octogenarians comprise the fastest growing population segment. Numerous reports have documented improved accomplishment of coronary artery bypass grafting in this high-risk cohort. But what is the quality of life after surgery, and how sustainable are the clinical benefits?

Methods: Sequential cross-sectional analyses were performed on 1062 consecutive patients 80 years old and older who underwent isolated on-pump coronary artery bypass grafting at a single institution from 1989 to 2001. After mean follow-up of 3.4 years (1 month-12.6 years), the Short Form 36 quality of life survey was administered to all survivors. Late follow-up for survival was performed after a mean 5.6 years (1 month-17.9 years). Multivariate analyses assessed risk factors associated with operative mortality, Short Form 36 selfassessment, and late survival.

Results: Mean age at operation was $83.1 \pm 2.8$ years (range, 80-99 years). Overall in-hospital mortality was $9.7 \%$, decreasing progressively to $2.2 \%$ during the course of the study. At midterm follow-up, $97.1 \%$ of patients were in Canadian Cardiovascular Society class I or II; Short Form 36 scores were comparable to age-adjusted norms in both physical and mental health summary scores. Actuarial survivals were $42.2 \% \pm 1.5 \%$ at 7 years and $9.9 \% \pm 1.4 \%$ at 14 years. Median survival was 5.9 years; 5.2 years for male patients and 6.7 for female patients $(P=.004)$.

Conclusions: The risk of coronary artery bypass grafting for octogenarians now rivals that of a younger population. Midterm quality of life and long-term survival approach those of the general population. ( $\mathrm{J}$ Thorac Cardiovasc Surg 2011;141:394-9)

3 Supplemental material is available online.

Elderly persons represent the fastest growing segment of the population. It is projected that the number of citizens older than 75 years will quadruple in the next 50 years. ${ }^{1}$ Nearly $40 \%$ of octogenarians have symptomatic cardiovascular disease, which accounts for more than half of the mortality in this age group. ${ }^{2}$ Multiple series have demonstrated the ability to perform cardiac surgery on this cohort with elevated but improving mortality and morbidity. ${ }^{3,4}$ The key questions that must be addressed are as follows: (1) Do the relief of symptoms and improvements in functional status

From the Florida Heart Research Institute, Miami, and Mount Sinai Medical Center, Miami Beach, Fla.

Disclosures: Authors have nothing to disclose with regard to commercial support.

Received for publication Oct 21, 2009; revisions received Jan 23, 2010; accepted for publication May 5, 2010; available ahead of print June 10, 2010.

Address for reprints: Paul A. Kurlansky, MD, Florida Heart Research Institute, 4770

Biscayne Blvd, Suite 500, Miami, FL 33137 (E-mail: DrWU18@aol.com).

0022-5223/\$36.00

Copyright (c) 2011 by The American Association for Thoracic Surgery doi: $10.1016 /$ j.jtcvs. 2010.05 .003 and quality of life (QOL) warrant the increased risk and expense of surgical therapy in this more fragile elderly population? (2) How sustainable are the clinical benefits? To address these issues, sequential cross-sectional followup was conducted consisting of a large cohort of patients 80 years old and older from a single community surgical practice who underwent isolated coronary artery bypass grafting $(\mathrm{CABG})$ for symptomatic coronary artery disease.

\section{MATERIALS AND METHODS}

For definitions of terms, see online Appendix E1. This report involves 1062 consecutive patients 80 years old and older who underwent isolated CABG between January 1989 and December 2001. Waiver of informed consent to conduct the study was obtained from the institutional review board. There were 651 men $(61.3 \%)$ and 411 women $(38.7 \%)$, with a mean age of $83.1 \pm 2.8$ years (range, $80-99$ years). The coronary and perioperative risk factors and coronary angiographic findings documented in the series are summarized in Table 1.

A patient's preoperative anginal symptoms were as defined by the Canadian Cardiovascular Society (CCS). Patients with unstable angina included those with CCS class III or IV symptoms. There were 64 patients $(6.0 \%)$ in class II, 502 patients $(42.3 \%)$ in class III, and 496 patients $(46.7 \%)$ in class IV.

\section{Operative Data}

The operation was performed electively in 832 cases $(78.3 \%)$, urgently in 162 cases $(15.3 \%)$ and on an emergency basis in 68 cases $(6.4 \%)$. A total 

Abbreviations and Acronyms
$\mathrm{CABG}=$ coronary artery bypass grafting
$\mathrm{CCS}=$ Canadian Cardiovascular Society
ITA $=$ internal thoracic artery
PCI = percutaneous coronary intervention
$\mathrm{QOL}=$ quality of life
SF-36 $=$ Short Form 36

of 3884 coronary artery grafts were performed (mean, 3.7 per patient; range, 1-6). The left internal thoracic artery (ITA) was used for grafting in 442 cases $(41.5 \%)$, and its use increased during the course of the study. All operations were performed with the assistance of cardiopulmonary bypass, moderate hypothermia, aortic crossclamping, and cold sanguineous cardioplegic arrest. The mean cardiopulmonary bypass time was $61.2 \pm 21.7 \mathrm{~min}-$ utes (range, 10-240 minutes), and the mean aortic crossclamp time was $31.7 \pm 15.8$ minutes (range, $4-140$ minutes).

\section{Data Collection and Management}

Perioperative data were obtained by prospective review of each patient's hospital record, catheterization reports, cinematic angiograms, and echocardiography. Follow-up information was obtained through comprehensive questionnaires and by telephone interviews with surviving patients, their family members, or their personal physicians. Follow-up data included activity level, current symptoms, diagnostic tests, occurrence of late cardiac events, medications being taken, and an assessment of QOL. Moreover, patients were asked to describe their anginal status and were ranked according to the CCS classification system.

A patient registration form and a patient follow-up form were completed for each patient in the study at the time of midterm follow-up. These data collection instruments provided standardized reporting of each patient's clinical status before and after the operation. When patients could not be located, the Social Security Death Index database (available at http://genealogy. rootsweb.com) was used to obtain patient mortality information. The capability to identify deaths in the Social Security Death Index is between $92 \%$ and $99 \%$ according to the unique identifiers available. ${ }^{5}$

QOL assessment was conducted with the Short Form 36 (SF-36) developed by Ware and associates. ${ }^{6}$ The SF-36 is a standardized instrument comprised of 36 items designed to measure 8 dimensions of overall health and 2 summary components, a physical health score and a mental health score.

Cross-sectional follow-up was performed in 2001 and included the patient's clinical status and QOL assessment. A second cross-sectional analysis with the Social Security Death Index was conducted in 2007 regarding survival status. Patients who could not be contacted during the course of the study through various means or were not identified in the Social Security Death Index were documented as unavailable for follow-up. A 98.6\% follow-up was obtained with 15 patients unavailable for follow-up.

\section{Statistical Analysis}

Data are presented as frequency distributions and simple percentages. Values of continuous variables are expressed as mean \pm SD. Univariate analysis of selected preoperative and postoperative discrete variables was accomplished by $\chi^{2}$ test, the continuity-adjusted $\chi^{2}$ analysis, or a 2-tailed Fisher's Exact test, with the appropriate degrees of freedom to test for the equality of proportions in the case of categorical variables. Two-sample Student $t$ tests (2-tailed) were used to test for the equality of the means of continuous variables. To identify predictors of hospital mortality, a multivariate analysis by forward stepwise logistic regression of preoperative and intraoperative variables was performed. For a listing of covariates used to predict in-hospital mortality, see online Appendix E2. A Cox proportional hazards regression model was used to discern the influence of multiple clinical variables on late survival. Regression coefficients and odds ratios with $95 \%$ confidence intervals were calculated to determine the relative influence of each covariate on the survivor function. Coefficients were computed by the method of maximum likelihood. For a listing of covariates used to predict late mortality, see online Appendix E3. A stepwise multivariate linear regression model was constructed to determine independent predictors of physical and mental health summary scores on the SF-36. For a listing of covariates used to predict physical and mental summary scores, see online Appendix E4).

Patient survival was expressed by actuarial analysis according to the method of Kaplan and Meier, with time zero as the date of operation and late death as the end point (with variability expressed as SEM). Patients alive at the last follow-up were included as right-censored values in the analysis. The equality of survival distribution was tested with the log-rank algorithm. Data collected were analyzed with the biostatistical capabilities of the Number Cruncher Statistical Systems (Kaysville, Utah).

\section{RESULTS}

Hospital complications included reoperation for bleeding in 34 patients $(3.2 \%)$, perioperative myocardial infarction in 16 patients $(1.5 \%)$, low cardiac output in 172 patients $(16.2 \%)$, cardiac arrest in 83 patients $(7.8 \%)$, renal insufficiency in 105 patients $(9.8 \%)$, respiratory insufficiency in 189 patients $(17.8 \%)$, cerebrovascular accident in 34 patients $(3.2 \%)$, and deep sternal infection in 16 patients $(1.5 \%)$. The overall incidence of postoperative morbidity for the group was acceptable, with most patients $(67.0 \%$, $\mathrm{n}=712$ ) having no hospital complications. The average postoperative stay for patients was $12.1 \pm 9.3$ days.

The overall in-hospital mortality for the series was $9.7 \%$ (97/1062), but it declined during the course of the study, decreasing to $2.2 \%$ in the most recent years (Figure 1). Mortalities were $8.8 \%$ (57 of 651 ) for men and $9.7 \%$ (40/411) for women $(P=.59)$. The elective procedure mortality was $8.3 \%(64 / 768)$, the urgent procedure mortality was $11.0 \%$ (16/146), and the emergency and salvage mortality was $33.3 \%(17 / 51)$. A within-group comparison of mortalities for elective versus nonelective procedures revealed a significant difference $(P=.002)$. Mortalities were $10.2 \%(88 /$ $948)$ for first operation and $8.6 \%(9 / 105)$ for reoperation.

To identify independent correlates of hospital mortality, preoperative and intraoperative variables were entered into a forward stepwise logistic regression model. Date of surgery $(P=.006), \operatorname{arrhythmia}(P=.004)$, abnormal ejection fraction $(P=.010)$, renal insufficiency $(P=.001)$, nonelective surgery $(P=.015)$, conduit type (no ITA, $P=.030$ ), and perfusion time (cardiopulmonary bypass time, $P=.011$ ) were correlated with in-hospital mortality (Appendix Table E1).

QOL and initial clinical follow-up data were collected for 950 patients discharged from the hospital $(98.4 \%)$. The initial follow-up ranged from 1.0 months to 12.6 years (mean, 3.4 years). The cumulative follow-up for the series was 3251.2 patient-years.

On completion of the QOL follow-up, many current survivors had clinical and functional improvement and were 
TABLE 1. Patient preoperative clinical variables and risk factors for patients 80 years old and older undergoing isolated coronary artery bypass grafting

\begin{tabular}{|c|c|}
\hline No. of patients & $1062(100.0 \%)$ \\
\hline \multicolumn{2}{|l|}{ Sex (no.) } \\
\hline Male & $651(61.3 \%)$ \\
\hline Female & $411(38.7 \%)$ \\
\hline \multicolumn{2}{|l|}{$\operatorname{Age}(y)$} \\
\hline Mean $\pm \mathrm{SD}$ & $83.1 \pm 2.8$ \\
\hline Range & $80-99$ \\
\hline \multicolumn{2}{|l|}{ Coronary risk factors (no.) } \\
\hline Family history of coronary artery disease & $211(19.9 \%)$ \\
\hline Hypertension & $669(65.8 \%)$ \\
\hline Hyperlipidemia & $337(31.7 \%)$ \\
\hline Smoking history & $234(22.0 \%)$ \\
\hline Diabetes mellitus & $277(26.1 \%)$ \\
\hline \multicolumn{2}{|l|}{ Perioperative risk factors (no.) } \\
\hline Renal dysfunction & $141(13.3 \%)$ \\
\hline Cerebrovascular disease & $161(15.2 \%)$ \\
\hline Peripheral vascular disease & $202(19.0 \%)$ \\
\hline Previous myocardial infarction & $609(57.3 \%)$ \\
\hline History of congestive heart failure & $278(26.2 \%)$ \\
\hline Unstable angina & $887(83.5 \%)$ \\
\hline \multicolumn{2}{|l|}{ Coronary angiography (no.) } \\
\hline Three-vessel disease & $953(89.7 \%)$ \\
\hline Two-vessel disease & $94(8.9 \%)$ \\
\hline Single-vessel disease & $15(1.4 \%)$ \\
\hline Left main disease $(>0.5)$ & $323(30.4 \%)$ \\
\hline \multicolumn{2}{|l|}{ Ejection fraction (no.) } \\
\hline$>0.5$ & $434(40.9 \%)$ \\
\hline $0.3-0.5$ & $453(42.7 \%)$ \\
\hline$<0.3$ & $156(14.7 \%)$ \\
\hline Not determined & $19(1.8 \%)$ \\
\hline \multicolumn{2}{|l|}{ Surgical history (no.) } \\
\hline First operation & $948(89.3 \%)$ \\
\hline Reoperation & $114(10.7 \%)$ \\
\hline
\end{tabular}

conducting their activities of daily living. There were $97.1 \%$ of the patients in CCS class I or II at the time of this followup, and $78.9 \%$ reported similar or improved health status compared with 1 year previously. The freedoms from major adverse cardiac events were $97.7 \% \pm 0.8 \%$ at 5 years and $96.3 \% \pm 4.6 \%$ at 10 years.

QOL assessment was conducted for all survivors willing and able to complete the SF-36 $(\mathrm{n}=545,98.2 \%)$. Table 2 gives the means and SDs for each of the 8 health scale scores as well as the physical and mental health summary component scores. A comparison of the study group's responses with age-adjusted norms revealed differences between the groups. Age-adjusted norms were significantly higher in physical functioning $(P=.001)$ and mental health, although the latter comparison did not achieve statistical significance. The study group scored significantly higher in role physical $(P=.001)$, bodily pain $(P=.001)$, and role emotional $(P=.004)$. In the physical health and mental health summary scores, the study group scored higher in both areas;

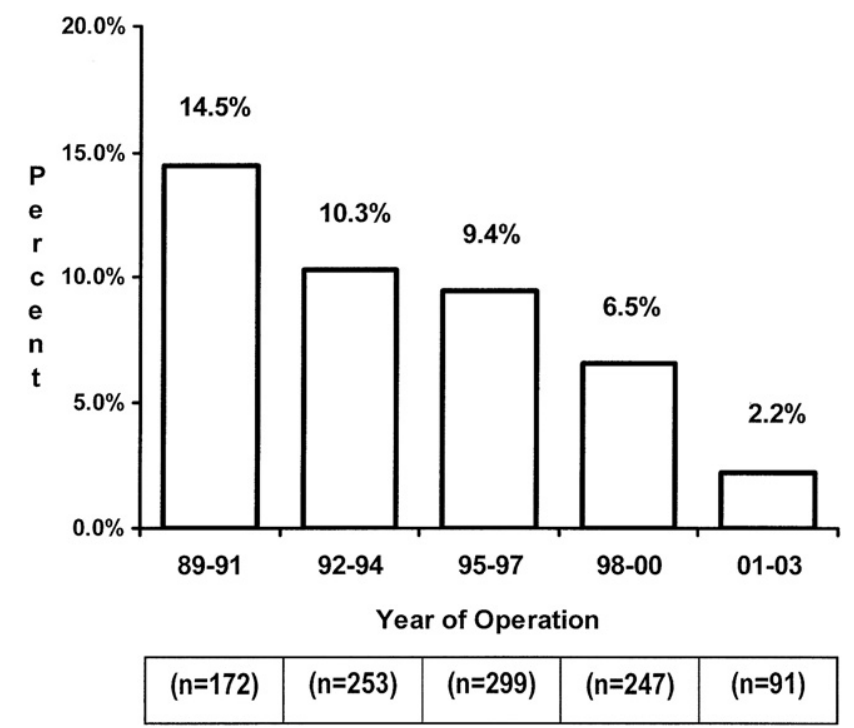

FIGURE 1. In-hospital mortality according to year of operation.

however, these differences did not achieve statistical significance. Independent predictors of the physical summary score were age $(P=.014)$, diabetes $(P=.001)$, and male sex $(P=.001)$; for the mental summary score, independent predictors were diabetes $(P=.004)$, previous myocardial infarction $(P=.022)$, and surgical history $(P=.016)$. These findings clearly demonstrate that octogenarians undergoing CABG have a QOL comparable to age-adjusted norms.

Long-term survival follow-up with the Social Security Death Index was performed on 950 hospital survivors. This follow-up ranged from 1 month to 17.9 years (mean 5.6 years). The actuarial survival data for all patients $(\mathrm{n}=1062)$ are shown in Figure 2, A. Survivals were $42.2 \% \pm 1.5 \%$ at 7 years and $9.9 \% \pm 1.4 \%$ at 14 years. The median survival was 5.9 years. The survivals for patients 80 to 83 years old were $60.5 \% \pm 1.9 \%$ at 5 years and $27.5 \% \pm 1.9 \%$ at 10 years, with a median survival of 6.4 years. Survivals for patients 84 years old and older were $48.7 \% \pm 2.5 \%$ at 5 years and $18.0 \% \pm 2.2 \%$ at 10 years, with a median survival of 4.9 years. Comparison of survival distribution between these cohorts of patients generated a significant difference $(P=.001)$.

A comparison of survival by sex demonstrated survivals for male patients of $52.4 \% \pm 2.0 \%$ at 5 years and $21.6 \% \pm 1.8 \%$ at 10 years and survivals for female patients of $62.2 \% \pm 2.4 \%$ at 5 years and $27.7 \% \pm 2.4 \%$ at 10 years. This comparison also revealed a significant difference $(P=.004)$, demonstrating that women in this study had an enhanced survival relative to men. The median survivals were 5.2 years for male patients and 6.7 years for female patients (Figure 2, B; compare with http://www.cdc.gov/nchs/ data/nvsr/nvsr57/nvsr57_14.pdf, page 26).

To identify independent predictors of late death, a Cox proportional hazards regression model was created to 
TABLE 2. Short Form 36 quality of life health status scale scores for patients 80 old and older undergoing isolated coronary artery bypass grafting versus age-adjusted norms

\begin{tabular}{lccc}
\hline \multicolumn{1}{c}{ Scale } & $\begin{array}{c}\text { Study group } \\
(\mathbf{n}=\mathbf{5 4 5})\end{array}$ & $\begin{array}{c}\text { Age-adjusted } \\
\text { norm }(\mathbf{n}=\mathbf{2 6 4})\end{array}$ & $\boldsymbol{P}$ value \\
\hline Physical functioning & $44.9 \pm 30.2$ & $53.2 \pm 30.0$ & .001 \\
Role_physical & $61.5 \pm 44.7$ & $45.3 \pm 42.0$ & .001 \\
Bodily pain & $71.0 \pm 27.9$ & $60.9 \pm 26.0$ & .001 \\
General health & $57.8 \pm 21.4$ & $56.7 \pm 21.2$ & .492 \\
Vitality & $51.4 \pm 21.4$ & $50.4 \pm 23.6$ & .547 \\
Social functioning & $76.0 \pm 29.1$ & $73.9 \pm 28.8$ & .335 \\
Role—emotional & $72.2 \pm 41.2$ & $63.2 \pm 43.0$ & .004 \\
Mental health & $71.5 \pm 19.7$ & $74.0 \pm 20.2$ & .094 \\
Summary scores & & & \\
$\quad$ Physical health & $39.0 \pm 11.1$ & $37.9 \pm 11.2$ & .188 \\
$\quad$ Mental health & $50.9 \pm 10.5$ & $50.4 \pm 11.7$ & .541 \\
\hline
\end{tabular}

measure the effects of various prognostic factors on time to response (operation to late death). Cox regression analysis demonstrated the independent effects of 8 covariates on late death: age $(P=.001)$, male sex $(P=.004)$, peripheral vascular disease $(P=.001)$, congestive heart failure $(P=.001)$, cerebrovascular accident $(P=.001)$, preoperative renal insufficiency $(P=.003)$, postoperative renal insufficiency $(P=.002)$, and postoperative pulmonary insufficiency $(P=.005$; Appendix Table E2).

\section{DISCUSSION}

With an aging population, many of whom have coronary artery disease, the question of optimal management in a time of rising health care costs and decreasing resources becomes of paramount importance. From the data presented here, surgical revascularization can be offered with decreasing inhospital mortality, excellent interim QOL, and a long-term survival that rivals that of the general population. To appreciate the contribution that these findings can make to the difficult decision-making algorithm, it is important to address both the strengths and limitations of the available information.

This report presents the largest single-center follow-up study of octogenarians undergoing isolated CABG in a community hospital, and among the longest. It demonstrates what can be accomplished (and likely is being accomplished) in community hospitals across the country. Because this study reflects the work of a single surgical group in a specific setting, there is certainly a selection bias underlying both the referral base and surgical decision-making process. Because of the absence of data regarding patients not referred or not accepted for surgery, an algorithm for patient selection cannot be created. The clear delineation of risk factors for both in-hospital and late mortality, however, certainly helps to define a population at increased risk for diminished clinical benefits. Moreover, retrospective data demonstrate a survival advantage and cost benefit of surgical
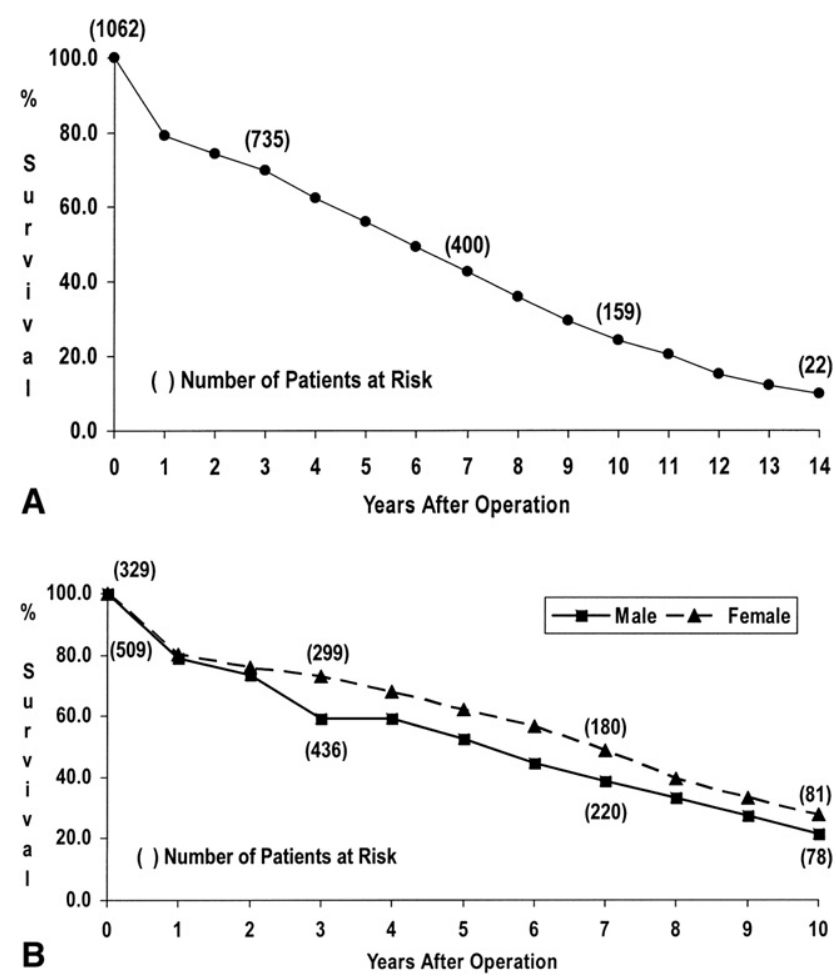

FIGURE 2. A, Actuarial survival of patients 80 years old and older after coronary artery bypass grafting. $\mathrm{B}$, Comparison of actuarial survival between male and female patients 80 years old and older after coronary artery bypass grafting.

versus medical management for octogenarians with coronary artery disease. ${ }^{7,8}$

Both prospective randomized trials and large observational studies have shown comparable survival and superior QOL at 1 year for interventional treatment (surgery or percutaneous coronary intervention [PCI]) versus medical treatment in this cohort. ${ }^{9-11}$ Within this context, the decreasing surgical mortality and excellent QOL demonstrated in this study would seem to suggest the need for further investigation with a larger patient population, rather than with a procedure-based database. This would better define the selection criteria for different therapeutic interventions in an elderly population.

In this consecutive longitudinal series, all patients received a single therapeutic intervention. This permits the evaluation of outcomes through time without the introduction of multiple confounding variables. Moreover, these findings serve as a baseline measurement against which alternative approaches can be evaluated. Medical management, interventional therapy, and surgical care are all rapidly evolving. In fact, the decreasing mortality that was observed in this study has been reported elsewhere, leading some researchers to conclude that age alone is no longer a significant predictor of mortality. ${ }^{12}$

Absence of a comparable younger cohort of patients does not permit this sort of comparison, although for the period 
studied, even within this cohort, age was a significant predictor of in-hospital mortality. Sample size limitation did not permit us to reasonably predict whether the reduced mortality observed in the most recent years of the study would predispose toward the loss of age as a significant predictor. Nonetheless, what clearly appears to be emerging is the concept of "physiologic" rather than "chronologic" age as a more relevant variable for patient evaluation. The data do not permit us to determine whether it is improved surgical, intensive care, and medical management or refined patient selection that accounts for the dramatic improvement in mortality. Indeed, there was no prospective or standardized methodology for patient selection. These decisions may well have evolved with time, just as surgical technique did with the documented increasing use of the ITA. Certainly the fact that the rate of complications in general did not decline while mortality did suggests that improvements in intensive care may have contributed to improved perioperative survival. Moreover, given that the risk profile of patients referred for surgery certainly increased, in an age of aggressive PCI, it is reasonable to assume that multiple factors in addition to patient selection account for these results.

The trend toward reduced mortality observed in this study mirrors that observed nationally for CABG during a similar period. ${ }^{13}$ Moreover, previous studies of CABG in octogenarians, both by this group and nationally, confirm lower mortality among patients receiving left ITA grafts. ${ }^{14,15}$ The increasing use of the left ITA graft with time may have accounted in part for the drop in mortality reported. Regardless of the reasons, the observation emerges from this data that in-hospital mortality in this elderly cohort now approaches that expected for CABG in the general population. The impact of this finding on the risk to benefit ratio used to make therapeutic decisions should not be underestimated.

The introduction of off-pump surgery has more recently been proposed as a potential method for reducing surgical mortality and morbidity in the elderly population. Although the results compared with more conventional on-pump surgeries have been mixed, ${ }^{16}$ most studies have demonstrated improvements in operative morbidity and mortality with the off-pump technique. ${ }^{17}$ No difference in QOL, however, has been discernible. ${ }^{18}$ The effects that innovative hybrid procedures and minimal extracorporeal circulation systems might have in further reducing surgical morbidity and improving outcomes have not yet been defined.

It may be reasonable to conclude that because of the fragility of and incremental risk of surgery in this elderly population PCI, with its attendant improvements, might represent a more prudent alternative. Long-term survival of octogenarians with multivessel disease, however, has been shown to be improved with CABG versus PCI. ${ }^{19}$ This finding may be related to the relationship between completeness of revascularization and improved survival in oc- togenarians. ${ }^{20}$ Although this study did not measure completeness of revascularization, it may be hypothesized that with an average graft/patient ratio of 3.7, the extent of myocardial revascularization may well have contributed to the favorable long-term survival. Unfortunately, there are no data available regarding any effects of evolving medical therapy that the patients may have experienced. Nor was there any information regarding social or other support systems that may have affected long-term survival and QOL.

Although our data do not permit a comparison of preoperative versus postoperative assessment of QOL, such improvement in this population has been well documented. ${ }^{21}$ Moreover, the low incidence of major adverse cardiac events and the transition from $89 \%$ of patients in CCS class III or IV preoperatively to $97.1 \%$ in CCS class I or II at the time of midterm follow-up demonstrates a marked improvement in this cohort. The remarkably low incidence of major adverse cardiac events may also reflect a reluctance to reintervene in elderly patients who have already undergone "maximum" myocardial revascularization. These data must be viewed with caution, because they were collected retrospectively from patients or families, rather than prospectively from medical records. The improved CCS statuses and good functional outcomes reported here indicate, however, that these patients not only have long-term survival but also return to an acceptable premorbid lifestyle in the mainstream of society.

Cardiac studies have demonstrated that physiologic parameters frequently do not correlate well with patient perception of health status. In fact, the opposite seems to be the case-patient perception of health status may be a powerful predictor of long-term mortality. ${ }^{22}$ It therefore becomes extremely important in the assessment of long-term outcomes with any therapeutic intervention to address separately the issues of clinical parameters and patient perception of QOL.

In this elderly high-risk population with multiple potential presenting comorbidities and unrelated health problems, the issue becomes even more compelling. Coronary artery disease itself carries a well-documented burden of depressed patient perception of QOL, ${ }^{23}$ so our findings that both physical and mental health summary scores were comparable to those of age-matched control subjects are remarkable. The comparison was actually with patients 75 years old and older, and because the SF-36 scores decline with age, the reported scores may be better than would be expected from a more closely age-matched control group.

Our specific finding of diminished physical functioning but improved perception of bodily pain and role physical may seem unusual; however, this is consistent with the findings of others ${ }^{24}$ and may reflect the underlying burden of disease rather than a limitation imposed by the surgery. Of particular interest in our study was the homogeneity of positive findings with time. Most of the research in this area 
centers on patient perception 1 to 2 years after surgery. Although practical considerations did not permit us to conduct the late follow-up that was conducted on mortality, our midterm follow-up spanned from 1 month to 12.6 years, with a mean of 3.4 years. Even so, date of surgery did not significantly impact QOL scores, providing further support for the durability of these results.

Although the predictors of QOL perception differed between the physical and mental health components, the powerful influence of diabetes was manifest in both summary scores. Interestingly, age and sex, which are well known as predictors of physical QOL perception, were not found to be predictive of the mental health summary score. The effect of previous myocardial infarction and previous surgery on perception of mental health well-being was somewhat unique in this study and merits further investigation.

As encouraging as these outcomes may be, the exigencies of modern health care have forced a paradigm shift. It is no longer sufficient merely to determine what is possible. With health care costs rising faster than the growth in the economy, we as a society are being challenged to evaluate whether a given intervention is financially viable as well as clinically feasible. Clearly, despite the improvements demonstrated with time, surgery in this elderly cohort is associated with longer hospital stays and is therefore more costly. Although this analysis lacks a cost-benefit model to study the financial effects, the data presented provide information essential to thoughtful evaluation of benefit and expense. Indeed, in light of the benefits of surgery for even unsuitable candidates, this therapy may represent an overall cost saving. ${ }^{7}$

In summary, this study demonstrates that CABG can be performed in a community setting on patients 80 years old and older with an increasingly acceptable and declining mortality, the expectation of sustainably improved patientperceived QOL, and survival comparable to that of the age-matched general population. These findings provide clarity and focus to the search for optimal therapy through surgical intervention in this increasingly prevalent and challenging group of patients.

We thank Dr Debra D. Guest for technical assistance in the preparation of this report.

\section{References}

1. Spencer G. U.S. Bureau of the Census: projections of the population of the United States, by age, sex and race: 1998-2080. Current population reports series P-25, No 1018. Washington, DC: US Government Printing Office; 1989.

2. National Center for Health Statistics. National health interview survey 19831985. Hyattsville (MD): The Center; 1986.

3. Peterson ED, Cowper PA, Jollis JG, Bebchuk JD, Delong ER, Mahlbaier LH. Outcomes of coronary artery bypass graft surgery in 24,461 patients aged 80 years or older. Circulation. 1995;92(Suppl. 2):II85-91.
4. Alexander KP, Anstrom KJ, Muhlbaier LH, Grosswald RD, Smith PK, Jones RH, et al. Outcomes of cardiac surgery in patients $\geq 80$ years: results from the National Cardiovascular Network. J Am Coll Cardiol. 2000;35:731-8.

5. Williams BC, Demitrack LB, Fries BE. The accuracy of the National Death Index when personal identifiers other than Social Security number are used. Am J Public Health. 1992;82:1145-7.

6. Ware J, Kosinski M, Keller S. SF-36. Physical and mental health summary scales: a user's manual. 2nd ed. Boston: The Health Institute, New England Medical Center; 1994.

7. Sollano JA, Rose EA, Williams DL, Thornton B, Quint E, Apfelbaum M, et al. Cost-effectiveness of coronary artery bypass surgery in octogenarians. Ann Surg. 1998;228:297-306.

8. Graham MM, Ghali WA, Faris PD, Galbraith PD, Norris CM, Knudtson ML, et al. Survival after coronary revascularization in the elderly. Circulation. 2002; 105:2378-84

9. Kaiser C, Kuster GM, Erne P, Amann W, Naegeli B, Osswald S, et al. Risks and benefits of optimized medical and revascularization therapy in elderly patients with angina-on-treatment analysis of the TIME trial. Eur Heart J. 2004;25: 10Q-42.

10. Kim J, Henderson RA, Pocock SJ, Clayton T, Sculpher MJ, Fox KA, et al. Health related quality of life after interventional or conservative strategy in patients with unstable angina or non-ST-segment elevation myocardial infarction: One-year results of the third Randomized Intervention Trial of Unstable angina (RITA-3). J Am Coll Cardiol. 2005;45:221-8.

11. Norris CM, Saunders LD, Ghali WA, Brant R, Galbraith PD, Graham M, et al. Health-related quality of life outcomes of patients with coronary artery disease treated with cardiac surgery, percutaneous coronary intervention or medical management. Can J Cardiol. 2004;20:1259-66.

12. Mamoun NF, Xu M, Sessler DI, Sabik JF, Bashour CA. Propensity matched comparison of outcomes in older and younger patients after coronary artery bypass graft surgery. Ann Thorac Surg. 2008;85:1974-9.

13. Ferguson BT, Hammill BC, Peterson ED, LeLong ER, Gover FL, for the STS National Database Committee. A decade of change-Risk profiles and outcomes for isolated coronary artery bypass grafting procedures, 1990-1999: A report from the STS national database committee and the Duke Clinical Research Institute. Ann Thorac Surg. 2002;73:480-90.

14. Kurlansky PA, Williams DB, Traad EA, Carrillo RG, Schor JS, Zucker M, et al Arterial grafting results in reduced operative mortality and enhanced long-term quality of life in octogenarians. Ann Thorac Surg. 2003;746:418-27.

15. Ferguson TB Jr, Coombs LP, Peterson ED. Internal thoracic artery grafting in the elderly patient undergoing coronary artery bypass grafting: Room for process improvement? J Thorac Cardiovasc Surg. 2002;123:869-80.

16. Tugtekin S, Kappert U, Alexiou K, Wilbring M, Nagpal AD, Matschke K. Coronary artery bypassing grafting in octogenarians - outcome with and without extracorporeal circulation. Thorac Cardiovasc Surg. 2007;55:407-11.

17. Demaria RG, Carrier M, Fortier S, Martineau R, Fortier A, Cartier R, et al. Reduced mortality and strokes with off-pump coronary artery bypass grafting surgery in octogenarians. Circulation. 2002;106(12 Suppl. 1):I5-10.

18. Jensen BO, Hughes P, Rasmussen LS, Pedersen PU, Steinbruchel DA. Health-related quality of life following off-pump versus on-pump coronary artery bypass grafting in elderly moderate to high-risk patients: a randomized trial. Eur J Cardiothorac Surg. 2006;30:294-9.

19. Dacey LJ, Likosky DS, Ryan TJ Jr, Robb JF, Quinn RD, DeVries JT, et al. Longterm survival after surgery versus percutaneous intervention in octogenarians with multivessel coronary disease. Ann Thorac Surg. 2007;84:1904-11.

20. Kozower BD, Moon MR, Barner HB, Moazami N, Lawton JS, Pasque MK, et al Impact of complete revascularization on long-term survival after coronary artery bypass grafting in octogenarians. Ann Thorac Surg. 2005;80:112-6.

21. Wilson MF, Baig MK, Ashraf H. Quality of life in octogenarians after coronary artery bypass grafting. Am J Cardiol. 2005;95:761-4.

22. Westin L, Nilstun T, Carlsson R, Erhardt L. Patients with ischemic heart disease: Quality of life predicts long-term mortality. Scand Cardiovasc J. 2005;39:50-4.

23. Xie J, Wu EQ, Zheng Z, Sullivan PW, Zhan L, Labarthe DR. Patient-reported health status in coronary heart disease in the United States. Circulation. 2008; 118:491-7.

24. Sjögren J, Thulin LI. Quality of life in the very elderly after cardiac surgery: a comparison of SF-36 between long-term survivors and an age-matched population. Gerontology. 2004;50:407-10. 


\section{APPENDIX E1. Definition of Terms}

\section{Preoperative Variables}

Hypertension was defined as blood pressure $(\geq 140 \mathrm{~mm}$ $\mathrm{Hg}$ systolic or $\geq 90 \mathrm{~mm} \mathrm{Hg}$ diastolic) on 2 occasions or current antihypertensive medication. Hypercholesterolemia was defined as a cholesterol level greater than $200 \mathrm{mg} / \mathrm{dL}$ on admission to the hospital. Renal insufficiency was defined as a documented history of renal failure with a creatinine level of $2.0 \mathrm{mg} / \mathrm{dL}$ or greater or current dialysis.

\section{Surgical Urgency}

Elective surgery was defined as an operation that could be deferred without increased risk of compromised cardiac outcome. Urgent surgery was defined as an operation required within 48 hours in an effort to prevent further clinical deterioration. Emergency surgery was defined as surgery for a patient with intractable angina or heart failure not responsive to aggressive clinical measures, a patient with impending infarction, or a patient in whom decompensation occurred in the cardiac catheterization laboratory, with measures such as defibrillation, extended cardiac massage, balloon counterpulsation, or inotropic support required.

\section{Postoperative Variables}

Respiratory insufficiency was defined requirement for ventilatory support for longer than 48 hours, tracheostomy, or both. Cerebrovascular accident was defined as a neurologic deficit that remained unresolved and was seen for more than 24 hours. Perioperative myocardial infarction was defined as a new onset of $\mathrm{Q}$ waves with or without elevation of myocardial enzymes or a substantial elevation of myocardial enzymes alone. Renal insufficiency was defined as a documented history of renal failure with a creatinine of $2.0 \mathrm{mg} / \mathrm{dL}$ or greater or current dialysis. Low cardiac output syndrome was defined as clinical evidence of hypotension, oliguria, and peripheral vascular constriction with normal or supranormal left ventricular filling pressure or a measured cardiac index of less than $2 \mathrm{~L} /\left(\mathrm{min} \cdot \mathrm{m}^{2}\right)$, necessitating the administration of catecholamines, use of an intra-aortic balloon pump, or both. Deep sternal infection was defined as instability of the sternum with positive wound cultures necessitating an additional surgical procedure, such as incision and drainage, débridement, or secondary closure. In-hospital mortality was defined as death occurring during the operation or the hospitalization in which the procedure was performed, or death occurring after discharge from the hospital but within 30 days of the surgical procedure, unless the cause was clearly unrelated to the operation.

\section{Major Adverse Cardiac Events}

Major adverse cardiac events included the combined incidence of nonfatal myocardial infarction, PCI, and reoperation for coronary artery disease.

\section{SF-36}

SF-36 refers to the Short Form 36, a standardized instrument comprising 36 items designed to measure 8 dimensions of overall health. ${ }^{6}$ These include physical functioning, social functioning, role limitations attributed to emotional problems, mental health, vitality (energy/fatigue), bodily pain, and general health perception. For each dimension, item scores are computed, totaled and converted into a scale, which ranges from 0 for worst health to 100 representing best health. Two summary components-a physical health summary and mental health summary score-are also computed.

\section{APPENDIX E2. Covariates Used to Predict In-Hospital Mortality}

\section{Preoperative Variables}

1. Age

2. Arrhythmia

3. Cerebrovascular disease

4. Congestive heart failure

5. Date of surgery

6. Diabetes

7. Diseased vessels

8. Dyslipidemia

9. Ejection fraction

10. Family history of coronary artery disease

11. Hypertension

12. Intra-aortic balloon pump

13. Male sex

14. Peripheral vascular disease

15. Previous myocardial infarction

16. Previous PCI

17. Renal insufficiency

18. Surgical history

19. Surgical urgency

20. Unstable angina

\section{Intraoperative Variables}

21. Conduit

22. Distal grafts

23. Perfusion time (in minutes)

\section{APPENDIX E3. Covariates Used to Predict Late Mortality}

\section{Preoperative Variables}

1. Age

2. Arrhythmia

3. Cerebrovascular disease

4. Congestive heart failure

5. Date of surgery

6. Diabetes

7. Diseased vessels 
8. Family history of coronary artery disease

9. Hyperlipidemia

10. Hypertension

11. Intra-aortic balloon pump

12. Male sex

13. Peripheral vascular disease

14. Previous myocardial infarction

15. Previous PCI

16. Renal insufficiency

17. Surgical history

18. Surgical urgency

19. Unstable angina

\section{Intraoperative Variables}

20. Conduit

21. Distal grafts

22. Perfusion time (in minutes)

\section{Postoperative Variables}

23. Atrial fibrillation

24. Cardiac arrest

25. Cerebrovascular accident

26. Low cardiac output

27. Perioperative myocardial infarction

28. Pulmonary insufficiency

29. Renal insufficiency

30. Reoperation for bleeding
APPENDIX E4. Covariates Used to Predict Physical and Mental Summary Scores on the SF-36

Preoperative Variables
1. Age
2. Diabetes
3. Diseased vessels
4. Dyslipidemia
5. Family history of coronary artery disease
6. Hypertension
7. Intra-aortic balloon pump
8. Male sex
9. Previous myocardial infarction
10. Renal disease
11. Surgical history
12. Surgical urgency
13. Unstable angina

\section{Postoperative Variables}

14. Atrial fibrillation

15. Cardiac arrest

16. Cerebrovascular accident

17. Low cardiac output

18. Perioperative myocardial infarction

19. Respiratory insufficiency

20. Renal insufficiency

21. Reoperation for bleeding 
APPENDIX TABLE E1. Multivariate analysis of preoperative and intraoperative variables associated with in-hospital mortality among patients 80 years old and older undergoing isolated coronary artery bypass grafting

\begin{tabular}{|c|c|c|c|c|c|c|}
\hline Predictor & $\beta$ Estimate & SE & $\chi^{2}$ & $P$ value* & Odds ratio & $95 \%$ Confidence interval \\
\hline \multicolumn{7}{|l|}{ Preoperative } \\
\hline Date of surgery & -0.0002 & .0001 & 7.54 & .006 & 1.0 & $1.0-1.0$ \\
\hline Arrhythmia & 0.6809 & .2289 & 8.52 & .004 & 2.0 & $1.3-3.1$ \\
\hline Abnormal ejection fraction & 0.6228 & .2494 & 6.61 & .010 & 1.9 & $1.1-3.0$ \\
\hline $\begin{array}{l}\text { Renal insufficiency } \\
\quad(\text { creatinine } \geq 2.0 \mathrm{mg} / \mathrm{dL})\end{array}$ & 0.9048 & .2581 & 11.26 & .001 & 2.5 & $1.5-4.1$ \\
\hline $\begin{array}{l}\text { Nonelective surgical } \\
\text { urgency }\end{array}$ & 0.6010 & .2406 & 5.93 & .015 & 1.8 & $1.1-2.9$ \\
\hline \multicolumn{7}{|l|}{ Intraoperative } \\
\hline Conduit (saphenous vein) & 0.5448 & .2554 & 4.73 & .030 & 1.7 & $1.0-2.8$ \\
\hline Perfusion time & 0.0117 & .0044 & 6.50 & .011 & 1.0 & $1.0-1.0$ \\
\hline
\end{tabular}

* Only significant differences $(P<.05)$ are listed.

APPENDIX TABLE E2. Preoperative, intraoperative and postoperative variables influencing late mortality as evidenced by Cox regression analysis in patients 80 years old and older undergoing isolated coronary artery bypass surgery grafting

\begin{tabular}{|c|c|c|c|c|}
\hline Predictor & Regression coefficient & SE & Relative hazard & $P$ value* \\
\hline \multicolumn{5}{|l|}{ Preoperative } \\
\hline Male sex & 0.2811 & 0.0979 & 1.3245 & .004 \\
\hline Age & 0.0601 & 0.0148 & 1.0619 & .001 \\
\hline Congestive heart failure & 0.4414 & 0.1002 & 1.5549 & .001 \\
\hline Peripheral vascular disease & 0.4210 & 0.1031 & 1.5234 & .001 \\
\hline $\begin{array}{l}\text { Renal insufficiency } \\
\quad(\text { creatinine } \geq 2.0 \mathrm{mg} / \mathrm{dL})\end{array}$ & 0.5105 & 0.1182 & 1.6661 & .001 \\
\hline Cerebrovascular accident & 1.1061 & 0.2146 & 3.0224 & .001 \\
\hline \multicolumn{5}{|l|}{ Postoperative } \\
\hline Respiratory insufficiency & 0.6766 & 0.1142 & 1.9671 & .001 \\
\hline $\begin{array}{l}\text { Renal insufficiency } \\
\quad \text { (creatinine } \geq 2.0 \mathrm{mg} / \mathrm{dL} \text { ) }\end{array}$ & 0.7237 & 0.1338 & 2.0620 & .001 \\
\hline
\end{tabular}

*Only significant variables $(P<.050)$ are listed. 